\title{
Can the craze for patient safety hinder a more holistic care of the person in the health care system?
}

\author{
Mamane Abdoulaye Samri, Daphney St-Germain \\ Nursing Sciences Faculty, Laval University, Quebec City, Canada
}

Received: January 31, 2018

Accepted: May 1, 2018

Online Published: June 27, 2018

DOI: $10.5430 /$ jnep.v8n12p9

URL: https://doi.org/10.5430/jnep.v8n12p9

\begin{abstract}
Background and objective: Since the publication of a report by the Institute of Medicine on the mortality associated with adverse events in the hospital, patient safety has become one of the essential objectives of the health care system. However, this movement tends to obscure the fundamental link between safety and quality of care in the health system. The study was aimed to demonstrate that the only focus on patient safety concept overshadow the more holistic care of the person and the population in the health care system.

Methods: Documentary research in the Pubmed database and the Google Scholar search engine, from 1999 to 2017.

Results and conclusion: Highly targeted safety research without addressing quality at first can only be a long-term panacea for current health policies. For cause, a one-way look at patient safety could lead to significant impacts at the population level. In order to get out of this craze, health system decision-makers would benefit from supporting clinical governance advocating humanistic and holistic strategies for interventions, engaging in a process of continuous improvement of the Quality of care more profitable in the long term. In order to overcome this craze, health system decision-makers would benefit from supporting clinical governance that advocates humanistic and holistic strategies for interventions, by engaging in a process of continuous improvement in the quality of care that is most beneficial in the long term. This posture is similar to Caring's well-known nursing model.
\end{abstract}

Key Words: Humanization of care, Caring, Quality of care, Patient safety, Health care system, Process of continuous improvement of the quality of care

\section{INTRODUCTION}

The strong interest in patient safety was revealed when the Institute of Medicine published, in 1999, to Err is Human. ${ }^{[1]}$ According to this report, 44,000 to 98,000 people died each year in American hospitals following medical errors that could be prevented. It was no longer necessary to attract the attention of Community professionals to study the issue and become the primary focus of interventions in health care organizations. ${ }^{[2]}$ Since then, patient safety has become a concern for both public health policies and professional health care practices. ${ }^{[3]}$ Consequently, the priorities focus on perfor- mance and good practice through the creation of frameworks conducive to the development of Excellence. ${ }^{[4]}$ Several institutions and organizations have been created, and many initiatives have begun, including the introduction of a culture of safety in health care settings, as advocated by the creation of the Canadian Institute for Patient Safety (CPSI) in 2004. It advocates a safe environment by transparently reporting and disclosing adverse events that occur. ${ }^{[5]}$ All these initiatives ultimately converge towards the promotion of safety of care. However, does this ultimate goal not overshadow the more comprehensive care of patients and the population in

\footnotetext{
*Correspondence: Mamane Abdoulaye Samri; Email: mamane.abdoulaye-samri.1@ulaval.ca; Address: 1050, avenue de la Médecine, Pavillon Ferdinand-Vandry, local 3645, G1V 0A6, Quebec, Canada. 
the health care system? Especially since in the face of this international concern for patient safety, authors such as Forest $^{[6]}$ are quick to compare it to the second revolution of the health system, after that of the years 1970; the one that has integrated health administration into public health policies to better meet the needs of the population. The aim of this article is to shed light on the concept of patient safety, in its holistic nature, and to highlight its considerations regarding quality of care.

\section{Methodology}

The synthesis of knowledge was carried out in the form of an integrative review. It is recommended to identify, analyze and synthesize current knowledge on a specific topic. ${ }^{[7]}$ In this perspective, we have circumscribed the review to the objective of our study, the impact of the patient safety craze on the management of patients and the population in the health care system. The research was carried out with the expressions: patient safety; Quality of care; Health care System; Bioethical values; Humanization of care from Google and Google Scholar and Pubmed, the main database of scientific articles where different disciplines convergence.

The inclusion criteria were: 1) published in English and French from 1999, the year of publication of the Institute of Medicine's report, to 2018; 2) whose title or keywords contained at least one of the terms of the search; 3 ) exposed the culture of patient safety and quality of care and describing the link between these two concepts in the health system. The exclusion criteria were: 1) published before 1999 (except for Donabedian's article, 1988, which served as a classic fundamental document for quality of care analysis); 2) treated the safety of patients in specific areas such as surgery, intensive care, emergencies. In fact, these are often focused on the implementation of technical safety devices (environmental arrangement standardization), or on the assessment of the impact or efficiency of the technical equipment (medicalsurgical robots, mobile applications) or drug products on patient safety.

The initial tracking enabled the identification of 123 articles. From a review of the summaries, 96 articles were excluded. 27 articles were retained. Although we do not be able to claim all the completeness of the method, it led to a sort of datas saturation, that means to significant repetition in information found out.

\section{ORIGINS OF THE CRAZE FOR SAFETY OF} CARE

The craze for patient safety is based in part on the innovation brought about by its updated culture in the hospital environment. The advocated culture of patient safety di- rects the rational identification of systemic factors that result in adverse events in order to correct conditions at risk and prevent their resurgence. ${ }^{[5]}$ In this case, it has shed light on the consequences of adverse events associated with the provision of care ${ }^{[8-10]}$ These include increased morbidity, prolonged hospital stays, increased mortality rates and associated costs. ${ }^{[11]}$ In addition, the fact that $37 \%$ of these events could be avoided ${ }^{[12]}$ justifies the attention given to patient safety on the one hand, and on the other hand, that it has become the pathway to improving care practices in the health system. However, this legitimate focus on detecting gaps in the health system may be too focused to sustainably improve care practices and, in this sense, hinder the optimization of system performance over the long term.

Moreover, while the procedures for the safety of care obey international standards, the fact remains that the consideration of safety of care varies according to the economy and the culture of States. ${ }^{[11,13]}$ In fact, the current trend for patient safety cannot be analyzed without recalling its origin, the U.S. care system. It is recognized for offering incomplete coverage, in a context of high performance and competition from medical players, and this in a deregulated economic market. ${ }^{[11]}$ In this logic, it seems normal, even essential, to vigorously defend the safety of care to "patient-clients"; the additional cost of the error being in the balance of private insurance. ${ }^{[14,15]}$ However, security is not and must not be the purpose of a system, but rather one of its characteristics. ${ }^{[16]}$ In fact, because of bioethical values, the safety of care is the minimum that a health service can offer to its patients. In Canada, the Health Act defines the basis of the values on which professionals must create the conditions necessary to protect the population.

\section{BACK TO THE SOURCES OF HEALTH PRO- FESSIONAL'S BIOETHICAL VALUES}

At the heart of care delivery, health professionals are driven by bioethical values that guide their behaviors and attitudes. These refer to all the norms and principles that underlie their professional practice. ${ }^{[17]}$ Indeed, these professionals have an obligation to show beneficence; of non-mistrust; of fairness; Of justice in the delivery of care and to ensure the safety of patients as a whole. ${ }^{[18]}$ These core values are, in a way, a unifying anchor that guides the work of these professionals in terms of nurses. These essential values inherently include patient safety. Thus, as soon as the patient enters the health care system, the nurses are responsible for ensuring their safety until they are released, ${ }^{[17]}$ and to ensure that they do not return for nosocomial illness related to the treatment. To do this, a partnership relationship must be established between the nurse and the patient/family, which is operationalized by 
the role of advocacy that the nurse demonstrates in an interdisciplinary team. Also, bioethical values inherently include the commitment of professionals in a cycle of continuous improvement in the quality of care they provide.

\section{LINK SECURITY AND QUALITY AT THE FOREFRONT OF IMPROVING SYSTEM PER- FORMANCE}

It must be admitted that security and quality have similar references while not having the same ends. In 2009, WHO developed a conceptual document for an international classification of patient safety for the adoption of common terminology. Patient safety has been defined as reducing the risk of unnecessary harm associated with health care to an acceptable minimum. The latter is defined according to the context and the state of knowledge. ${ }^{[19]}$ Unnecessary harm includes all prejudices that may affect the physical, spiritual, psychological and psychosocial dimensions of the patient. In practice, however, patient safety seems to be still confined to a physical dimension that tends to obscure the other intrinsic dimensions of the person. ${ }^{[20,21]}$ Yet the care of the person naturally calls for this holistic support that goes beyond the punctual identification of an adverse event. It fits more into a process that links adverse event, risk management and prevention. In this sense, the notion of security should be linked to quality. ${ }^{[1]}$

The quality of care reflects the ability of a health system to ensure that each individual has the best possible outcome in terms of health, at least iatrogenic risk (WHO, 1992, cited by $\mathrm{ANAES}^{[22]}$ ). The quality of care is not limited to the detection of adverse events or medical errors, but is more in line with a posture promoting the health of the individual and the population in which all the actors involved have a responsibility. As such, patient safety can be seen as one of the many indicators of the quality of care.

For his part, Donabedian, ${ }^{[23]}$ an illustrious researcher in Health Administration, believes that the quality of care concerns all aspects of the health system: from procedures to results to governance. More specifically, it defines quality in its technical, relational and organisational components. While the technical components refer to the professional knowledge of the caregiver, the relational components correspond to the caregiver's ability to establish a relationship of trust with the patient. The latter often motivate patients to collaborate in their treatment plan. Finally, organizational components include all aspects of accessibility, continuity of care, fairness and geographic, economic and Social equality. ${ }^{[24]}$ The constant improvement of these components refers to a structured and dynamic approach better known as a proPublished by Sciedu Press cess of continuous improvement of the quality of care.

By aiming at a high-level performance of the system, continuous quality improvement is the optimum lever to mobilize all the assets of the organization, while paying particular attention to the development of Skills of professionals working there. ${ }^{[25]}$

\section{LIMITS OF A UNIDIRECTIONAL LOOK AND THE NECESSITY FOR OVERALL PERSON CARE IN THE HEALTH SYSTEM}

Force is to note that a system that does not target the continuous improvement of the quality of these services by aiming only at promoting the safety of care could jeopardize its essential values (equity, autonomy and efficiency) that underlie its very existence. ${ }^{[13]}$ This system will invest funds in costly and accessible technologies to a handful of individuals to the detriment of the majority of the population rather than solving the basic problem such as access to Care. ${ }^{[26]}$ However, the inequality linked to the accessibility of care services is a real problem which public health policies are confronted with to promote the health of the population. ${ }^{[27]}$ Thus, a system focused on patient safety will focus more on the reduction of adverse events on the one hand, and on the other hand, will focus its financial and human resources on the detection of its vulnerabilities rather than the multiplication of behaviors and potentially beneficial attitudes. ${ }^{[6]}$ Promoting excessive patient safety could even create a climate of suspicion in the organization that would inhibit innovation in the system.

In addition, several authors ${ }^{[28-32]}$ stipulate that a system that is too low-cost in performance and which imposes unrealistic rules and protocols on the safety of care of its actors is placed in a risk area. This can be explained by the fact that there will be illicit transgressions in professional practice that will make this unbalanced system migrate to a highly accident-prone area since the actors present will not find their account by individual advantages. For Braithwaite, Wears ${ }^{[33]}$ and Cuvelier, ${ }^{[16]}$ ultra-security could even be counterproductive if it does not take into account the complexity of the system. Valuing the continuous improvement of the quality of care offered by professionals can thus have a more satisfying individual impact and create a more rewarding work environment, being more proactive in the face of possible Problematic situations. This justifies the need for an increased commitment of everyone in a cycle of continuous improvement in the quality of care; This cycle allows for more upstream action against the system's shortcomings. ${ }^{[25]}$ Thus, by remaining proactive, the quality will be considered not only in its technical dimensions, but above all, in its interpersonal dimensions, like the humanistic nursing care 
as advocated by the Caring model of Watson. ${ }^{[34]}$ In this case, this approach ensures full and complete accessibility of care to all, avoiding only those who have received care, as currently advocated from a one-way perspective on patient safety. The health system would thus benefit from projecting an enlarged vision by integrating all of these components as Woolf ${ }^{[26]}$ demonstrates in the representation below. The caring already known as a nursing model then finds echo in an organizational perspective of continuous improvement in quality in the care system.

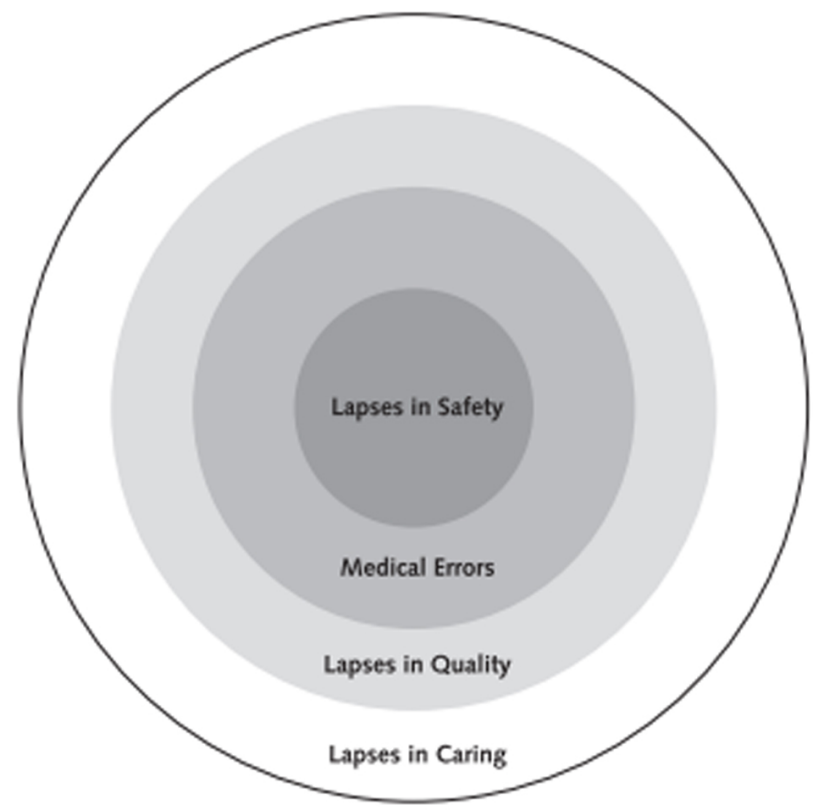

Figure 1. Organizational reference framework for health care service failures ${ }^{[26]}$

Woolf highlights Caring's prominence of caring in the health care system, which he apprehends as a circle of four concentric levels, representing, respectively, the errors related to the caring, the quality, the medical aspects and the safety. The caring corresponds to the first level, the most encompassing. Its errors bring together all the technical and organizational failures resulting from the neglect of the relational aspects, at all the links in the system. The four levels of this circle determine the results of care and the performance of the health system. Neglect or overestimation of one or more of these levels hinders the overall management of the patient and has a negative impact on the quality of the system. Yet one of the objectives of continuous quality improvement is to take all these levels into account in a proportionate manner.

Figure 1 highlights the need to adopt a philosophy of humanistic care in the health system that combines quality and safety. In this respect, the writings of St-Germain, Blais and Cara $^{[35]}$ underline the benefits of this approach. According to these authors, considering the person in all its entirety, the humanistic approach promotes the establishment of a relationship of trust, complicity between the caregiver and the patient conducive to a quality nursing practice. In fact, it optimizes the chances of collaboration and self-determination of the person himself in his treatment plan, guaranteeing a better result of care by reducing the risk of adverse events. On the other hand, the satisfaction of the completed duty will encourage the professional to continually engage in a cycle of continuous quality improvement. ${ }^{[36]}$ With such a perspective, the health system will ensure that its fundamental mission is fully fulfilled by systematically advocating continuous improvement in the quality of care. ${ }^{[35,37]}$ This will allow it to reconnect with its essential values in order to ensure its performance, its efficiency and its productivity. In addition, this makes it possible to credibility the health system by displaying the importance of creating a bond of trust with the population ${ }^{[22]}$ and its actors. However, establishing such a perspective requires adequate clinical governance advocating fundamental bioethical values, holistic management and a strong partnership with the patient as a person and his family interconnecting safety and quality through the promotion of continuous improvement in the quality of care. It involves the implementation of systemic and organizational approaches that put the well-being of the person (as a whole) as a focus at the end of the process of health cares and services. In this respect, the Caring-Disability Creation Process (DCP) Model proposed by St-Germain, Boivin and Fougeyrollas ${ }^{\text {[38] }}$ provides also a conceptual perspective to optimize the social integration and participation of the person in the community in a fully citizenship goal. The main focus of the person's integration and participation could then exceed the expectations, fullfilling physical, psychological, psychosocial and spiritual well-being dimensions of the individual. ${ }^{[39]}$ In other words, Woolf and St-Germain and coll., ${ }^{[21,35,38]}$ suggest approaches that work upstream, globally and rather fostering commitment about a continuous quality of cares improvement than targeting patient safety as a main goal. And, in this way, that is taking advantage of possibly more sustainable benefits.

\section{Conclusion}

From all of the foregoing, it is clear that a unidirectional approach to patient safety can have significant limitations that comprise the overall care of patients in the health system and prevent system from investing tangible resources to broaden its perspective towards continuous improvement in the quality of care; This one is more often oriented towards the detection of the middle faults. The repercussions can be reflected, among other things, by poor quality of care 
offered and the increase in social inequalities in health. In addition, this approach seems to reduce security to a physical and limited dimension in terms of sustainable health development. However, due to the bioethical values that health professionals must convey, the health care system should focus its initiatives more towards a cycle of continuous quality improvement. This concept would thus broaden the scope of action by soliciting the participation of all components of the health system, including the risk-prevention sector.

Moreover, in the face of the demands and challenges of globalization such as social inequalities in health, ageing of the population, accessibility to care and the performance of systems, the humanization of care is a necessity. Like Foucher, ${ }^{[40]}$ we believe that if the health system wants to optimize its performance and reconnect with its fundamental values, it must put the human in the foreground. It is not only "a matter of moral responsibility, but it is an indispensable factor for success". ${ }^{40]}$ As a result, it is essential that the health care system is no longer limited to discourses on patient safety or even quality. Decision-makers and health professionals must engage in a continuous improvement of the quality of care that promotes safe actions upstream. The study of the performance of health systems will well tell us, in the future, the economic and social impact of taking into account such a process of continuous improvement of the quality of care at the national population level and International. Can this unidirectional look at patient safety be a springboard to a full awareness of the limits dictated by a dehumanized system?

\section{BIO STATEMENTS}

Mamane Abdoulaye Samri, Student in Doctorate Community Health Program, Nursing Sciences Faculty, Laval University.

Daphney St-Germain, Ph. D., Associate Professor, Nursing Sciences Faculty, Laval University.

\section{CONFLicts OF INTEREST Disclosure}

No conflict of interest declared.

\section{REFERENCES}

[1] Institut Of Medicine. To Err is Human: Building a safer Health System. Washington: National Academy Press. Institute of Medicine; 1999.

[2] Cochrane BS, Hagins M, Picciano G, et al. La haute fiabilité en soins de santé: la création d'une culture et d'une mentalité favorisant la sécurité des patients. Healthcare management forum; SAGE Publications; 2017.

[3] Nascimento A. Sécurité des patients et culture de sécurité: une revue de la littérature. Ciência \& Saúde Coletiva. 2011; 16(8): 3591-602. https://doi.org/10.1590/S1413-81232011000900027

[4] Brault I, Roy D, Denis JL. Introduction à la gouvernance clinique: historique, composantes et conceptualisation renouvelée pour l'amélioration de la qualité et de la performance des organisations de santé. 2008.

[5] Institut Canadien pour la Sécurité des Patients. Cadre canadien d'analyse des incidents. 2012. Available from: http://www . patientsafetyinstitute.ca/fr/toolsresour ces/IncidentAnalysis/Documents/Canadian\%20Incident $\% 20$ Analysis $\% 20$ Framework $\% 20 \mathrm{FR}$. PDF

[6] Forest P. A new synthesis. International Journal of Health Policy and Management. 2014; 2(1): (1-3). PMid:24596900

[7] Souza MTd, Silva MDd, Carvalho Rd. Integrative review: what is it? How to do it? Einstein (São Paulo). 2010; 8(1): 1026. PMid:26761761 https://doi.org/10.1590/s1679-45082 010rw1134

[8] Vincent C, Aylin P, Franklin BD, et al. Is health care getting safer? BMJ: British Medical Journal. 2008; 337.

[9] De Marcellis-Warin N, Dufour G. Analyse des événements indésirables liés à la prestation des soins de santé: Démarche structurée et grille d'analyse. CIRANO; 2003.

[10] Michel P, Quenon JL, Djihoud A, et al. Quels événements indésirables graves dans les établissements de santé publics et privés en
France?: Principaux résultats eneis. Risques \& Qualité en milieu de soins. 2005; 3: 131-8.

[11] Brami J, Amalberti R. La sécurité du patient en médecine générale: Springer Science \& Business Media; 2010.

[12] Baker GR, Norton PG, Flintoft V, et al. The Canadian Adverse Events Study: the incidence of adverse events among hospital patients in Canada. Canadian Medical Association Journal. 2004; 170(11): 1678-86. PMid:15159366 https://doi.org/10.1503/ cmaj. 1040498

[13] Contandriopoulos AP. Inertie et changement. Ruptures, revue transdisciplinaire en santé. 2003; 9(2): 4-31.

[14] Batifoulier P. Capital santé: quand le patient devient client: La Découverte; 2014.

[15] Azam G. La santé, un bien économique. 2008. Available from: http://institutpolanyi.fr/la-sante-un-bien-commun/

[16] Cuvelier L. L'ingénierie de la résilience: un nouveau modèle pour améliorer la sécurité des patients? L'exemple de l'anesthésie. Santé publique. 2013; 25(4): 475-82. https://doi.org/10.3917/sp ub. 134.0475

[17] Melchior JP. De l'éthique professionnelle des travailleurs sociaux. Informations sociales. 2011; 167: 123-30.

[18] Kangasniemi M, Pakkanen P, Korhonen A. Professional ethics in nursing: an integrative review. Journal of Advanced Nursing. 2015; 71(8): 1744-57. PMid:25598048 https://doi.org/10.1111/ja n. 12619

[19] Runciman W, Hibbert P, Thomson R, et al. Towards an International Classification for Patient Safety: key concepts and terms. International Journal for Quality in Health Care. 2009; 21(1): 18-26. PMid:19147597 https://doi.org/10.1093/intqhc/mzn057

[20] St-Germain D, Allaire AS. L'infirmière en réadaptation physique.. vous connaissez? 2013: 10(3): 40-4.

[21] St-Germain D. Réflexions sur l'apport de la recherche inductive phénoménologique dans l'instauration d'une culture de sécurité réelle 
et efficace en contexte de réadaptation. Recherches qualitatives. 2010; 29(2): 185-99.

[22] Agence Nationale d'Accréditation et d'Évaluation en Santé. Les coûts de la qualité et de la non-qualité des soins dans les établissements de santé : états des lieux et propositions. 2004.

[23] Donabedian A. The Quality of Care: how can it be assessed ? JAMA. 1988; 260(12): 1743-8. https://doi.org/10.1001/jama. 1988. 03410120089033

[24] Sollecito W, Johnson JK. McLaughlin and Kaluzny's continuous quality improvement in health care: Jones \& Bartlett Publishers; 2011.

[25] Gardette V. Principes d'une démarche d'assurance qualité, évaluation des pratiques professionnelles. il faut chercher OMS ref. 2010.

[26] Woolf SH. Patient safety is not enough: targeting quality improvements to optimize the health of the population. Annals of Internal Medicine. 2004; 140(1): 33-6. https ://doi.org/10.7326/0003 -4819-140-1-200401060-00009

[27] Baum FE, Bégin M, Houweling TA, et al. Changes not for the fainthearted: reorienting health care systems toward health equity through action on the social determinants of health. American Journal of Public Health. 2009; 99(11): 1967-74. PMid:19762660 https://doi.org/10.2105/AJPH. 2008.154856

[28] Amalberti R. Les effets pervers de l'ultra sécurité en médecine. Revue hospitalière de France. 2002; 489: 7-15.

[29] Amalberti R. Piloter la sécurité: Théories et pratiques sur les compromis et les arbitrages nécessaires: Springer Science \& Business Media; 2013.

[30] Hollnagel E. Resilience: the challenge of the unstable. Resilience engineering: CRC Press; 2017. 21-30 p.

[31] Bégin L. Cinq questions d'éthique organisationnelle. Montréal: Nota bene; 2014. $220 \mathrm{p}$.
[32] Amalberti R, Hourlier S. Human error reduction strategies in health care Handbook of Human Factors and Ergonomics in Health Care and Patient Safety. 2nd ed. 2011. 400 p.

[33] Braithwaite J, Wears RL, Hollnagel E. Resilient health care: turning patient safety on its head. International Journal for Quality in Health Care. 2015; 27(5): 418-20. PMid:26294709 https://doi .org/10 .1093/intqhc/mzv063

[34] Watson J, Foster R. The Attending Nurse Caring Model@: integrating theory, evidence and advanced caring-healing therapeutics for transforming professional practice. Journal of Clinical Nursing. 2003; 12(3): 360-5. https : //doi.org/10.1046/j.1365-2702. 2003 $.00774 . \mathrm{x}$

[35] St-Germain D, Blais R, Cara C. La contribution de l'approche de caring des infirmières à la sécurité des patients en réadaptation: une étude novatrice. Recherche en soins infirmiers. 2008; 4: 57-69. https://doi .org/10.3917/rsi.095.0057

[36] Loubat J-R. La démarche qualité en action sociale et médico-sociale2e éd: Dunod; 2015.

[37] St-Germain D. The rehabilitation nurse then and now: From technical support to human potential catalyst by Caring-Disability Creation Process Model in an interprofessional team. Journal of Nursing Education and Practice. 2014; 4(7): 54-61. https : //doi .org/10.543 0/jnep.v4n7p54

[38] St-Germain D, Boivin B, Fougeyrollas P. The Caring-Disability Creation Process Model: a new way of combining Care in nursing and Rehabilitation for Better Quality of Services and Patient Safety. Disability and Rehabilitation. 2011; 33: 2105-2113. PMid:21401337 https ://doi.org/10.3109/09638288.2011.560330

[39] St-Germain D. Community and Interprofessional Collaboration in Physic Rehabilitation Area, Which Place for Patient Safety for the Individuals? Examines in Physical Medicine and Rehabilitation. 2018; 1(3): 1-2.

[40] Foucher JL. Ressources inhumaines. Paris: Bourin; 2005. 269p. 